\title{
The British fournal of Social Medicine: what was in a name?
}

\author{
Shaun Murphy, George Davey Smith
}

This Journal was founded as the British fournal of Social Medicine in 1947. It became the British fournal of Preventive and Social Medicine in 1953, and took on its current title, the fournal of Epidemiology and Community Health, in 1978. The founding of the Journal reflected the growing interest in social medicine seen during the middle decades of this century. The failure to sustain this enthusiasm beyond its initial peak might be viewed as either indicative of a lack of substance in the discipline, or of its strategic incorporation within a broader view of the public health function. A re-examination of this could be helpful at a time when there is the potential to renew interest in the social origins and social prophylaxis of illness.

While George Rosen ${ }^{1}$ and Dorothy Porter ${ }^{2}$, among others, have discussed the ideas of the pioneers of social medicine, little attention has been paid to the actual content of their early work. This paper looks back at the vision of the early practitioners of social medicine in this country, and contrasts the ideas with the practice as evidenced by the papers appearing in this Journal in its first five years. The reasons for the subsequent fall from favour of the term social medicine are discussed and finally the content of some of the Journal's recent papers is considered.

\section{The emergence of social medicine}

British reformers were at the forefront of enquiries into the health and living conditions of workers in industrial towns in the 19th century, and it is perhaps surprising that the formal discipline of social medicine was late to develop in Britain in comparison to other European countries. George Rosen surveyed the development of social medicine in the latter part of the 19th century and the first half of this century, ${ }^{1}$ and described activities in Belgium, Germany, the Scandinavian countries, the Soviet Union, Italy, France, Switzerland, Holland, Yugoslavia, and Czechoslovakia.

A great deal of work was done in the Germanspeaking countries in the period leading up to the First World War, ${ }^{3}$ but the intellectual advances of this time have tended to be overshadowed because many (but not all) of the leading figures combined ideas of social medicine, as discussed in this paper, with theories of racial hygiene or eugenics. ${ }^{4}$ This rather startling combination of ideas by the standards of contemporary ideological compartmentalisation also occurred in some other European countries, and the United States.

Interest in the social aspects of health and disease gathered momentum in Britain in the 1920s and 1930s. The Peckham Health Centre was opened in London in 1926 by G Scott Williamson and Innes Pearse, and a number of publications appeared, including G C M M'Gonigle and J Kirby, Poverty and Public Health, (1937); John Boyd Orr, Food, Health and Income (1936); and Richard Titmuss, Poverty and Population (1938).

But the 1940s was the time at which interest in, and support for, social medicine reached a high point in Britain. As well as the creation of this Journal, four chairs in social medicine were established and these were taken by John Ryle at Oxford, Francis Crew in Edinburgh, Thomas McKeown at Birmingham, and William Hobson at Sheffield. In addition, the Medical Research Council created a Social Medicine Research Unit at the Central Middlesex Hospital and appointed Jerry Morris as its director, and Richard Titmuss as deputy director. In the five years from 1947 to 1951, Francis Crew and Lancelot Hogben were editors of the British Fournal of Social Medicine and they were joined by Thomas McKeown in 1950 .

John Ryle, one of the most eminent physicians in London in the early 1930s, came into social medicine with an international reputation for the development of certain diagnostic aids. ${ }^{2} \mathrm{He}$ became the Regius Professor of Physic at Cambridge in 1935, and moved to the first Chair in Social Medicine at Oxford in 1943. Dorothy Porter has pointed out that it was rather remarkable that a clinician of such stature should

“. . . interest himself in a field which, in Britain since the mid-nineteenth century, was considered the province of the public health officer."

Francis Crew, a distinguished doctor and geneticist, became Army Director of Medical Research (holding the rank of brigadier) from 1942-46. Jerry Morris also became a senior officer in the Royal Army Medical Corps, and had been a physician to Nottingham City Council before that.

Remarkably, for someone who was to become a professor at the London School of Economics, Richard Titmuss was not a grad- 
uate, having worked for over 10 years in the insurance business. He began studying social issues and related statistical data in his own time, and published a series of increasingly influential works on population, poverty, and wealth. ${ }^{6}$

Thomas McKeown, still at a relatively early stage in his career when he took the chair at Birmingham, soon established himself as a prolific contributor to demography, nascent health services research, and epidemiology.

William Hobson, a specialist in occupational medicine, had rather less influence on the development of the discipline than the other founding professors, but his appointment reflected the perceived importance of occupational influences on health in this period of social medicine. ${ }^{7}$

The establishment of an Institute of Social Medicine at Oxford under so eminent a clinician as John Ryle attracted considerable contemporary interest. The Regius Professor of Medicine at the University of Oxford, Farquhar Buzzard believed that, as with remedial medicine, there should be research centres devoted entirely to the subject with close links to both university medical schools and hospitals. ${ }^{8} \mathrm{He}$ considered that there should be a long term aim to institutionalise social medicine and added,

". . . and I entertain no doubt that we shall see this development in several centres of this country in the next few years...".

In just a few years social medicine had gone from being unrepresented in British medical schools to being a self confident discipline with institutions and a journal of its own.

\section{The vision of social medicine}

John Ryle set out his view of social medicine in his paper in the BMF in 1943, "Social Medicine: Its Meaning and Scope". 9 In a section headed "The Third Epoch of Preventive Medicine", he wrote,

". . . the first epoch was occupied with the disclosure of the appalling conditions in which the working classes then lived, of the prevailing lack of sanitary provisions, of the hovel-like homes, of the defective and contaminated water supplies, of the high death rates; and with the earlier endeavours to limit the ravages of the acute infectious diseases - typhus, typhoid, smallpox, cholera, and the malignant scarlet fever of those days.

The second epoch has continued and extended the work of the first, but it has also witnessed the attack on the chronic infective diseases - tuberculosis, venereal disease, and now (we may hope), with an improved understanding of its intimate connections with poverty and crowding and streptococcal throat infections, on rheumatic fever. . ."

And in conclusion he said,

"The idea that many non-infective diseases can also be considered as preventable and so may eventually be brought within the jurisdiction of a nation's health authority has sunk more slowly into the consciousness both of the profession and of the laity."

In a paper to the New York Institute on Social Medicine in $1947,{ }^{10}$ he came back again to definition,
"Social medicine and social pathology should, as their names suggest, be considered respectively as the medicine and pathology of families, groups, societies, or larger populations."

And in the same paper he made one of his many comments on how little the social aspects of disease were part of the medical curriculum.

"In general, the newly qualified doctor embarks upon his career steeped in the ideas of individual pathology, moderately well versed in therapeutic techniques, and with a smattering of psychology, but almost ignorant of social pathology, knowing little of the incidence of diseases and their mortalities and secular trends or of the social factors which are, in part or whole, responsible for their inception or continuance."

The first issue of the British fournal of Social Medicine, which appeared in January 1947, contained a notice to contributors (to be found on the back of the journal cover and unfortunately generally missing from bound volumes) which defined social medicine as,

"That branch of science which is concerned with: (a) biological needs, interactions, disabilities, and potentialities of human beings living in social aggregates; (b) numerical, structural, and functional changes of human populations in their biological and medical aspects. To a large extent its methods must necessarily be statistical, involving the use of numerical data obtained either from official sources or from special field investigations, and interpreted in the light of established findings of the laboratory and of the clinic. Social medicine takes within its province the study of all environmental agencies, living and non-living, relevant to health and efficiency, also fertility and population genetics, norms and ranges of variation with respect to individual differences and, finally, investigations directed to the assessment of a regimen of positive health."

One wonders what aspiring contributors to the Journal made of this rather long-winded and opaque attempt to describe social medicine. It can be inferred that Lancelot Hogben was the main author of this text since Francis Crew had given a rather clearer answer to the question of what is social medicine three years earlier, ${ }^{11}$ in which he gave prominence to the study of the social causes of ill health and the use of sociological methods.

"Social medicine rooted both in medicine and in sociology includes preventive medicine in this sense as well as industrial medicine, which is surely more than a variant of toxicology, but it differs from these in that it is not merely or mainly concerned with the prevention and elimination of sickness, but is concerned also and especially with the study of all social agencies which promote or impair the fullest realisation of biologically and socially valuable human capacities. It includes the application to problems of health and disease of sociological concepts and methods."

Jerry Morris and Richard Titmuss, in their celebrated paper on rheumatic heart disease, ${ }^{12}$ asserted that the relationship between health and social circumstances had been demonstrated, but that further work on the dynamic relationship between the two was needed.

"In general it may now be said that the dependence of good health on favourable social circumstances has been amply demonstrated. The 


\begin{tabular}{|c|c|c|}
\hline & 1 & $\begin{array}{l}\text { Broad definition of social } \\
\text { medicine }\end{array}$ \\
\hline \multicolumn{2}{|l|}{$\begin{array}{l}\text { Clinical and laboratory work } \\
\text { applied to individuals or small } \\
\text { groups }\end{array}$} & Health studies of populations \\
\hline & \multicolumn{2}{|c|}{\begin{tabular}{|l|l|} 
& \\
\end{tabular}} \\
\hline & 2 & Ryle's emphasis \\
\hline \multicolumn{2}{|l|}{$\begin{array}{l}\text { Aetiology and treatment of the } \\
\text { acute and chronic infectious } \\
\text { diseases }\end{array}$} & $\begin{array}{l}\text { Aetiology and treatment of the } \\
\text { non-infectious diseases. The } \\
\text { study of health itself }\end{array}$ \\
\hline & \multicolumn{2}{|c|}{$\begin{array}{l}+ \\
\end{array}$} \\
\hline Quantitative research & 3 & Qualitative research \\
\hline $\begin{array}{l}\text { Primarily epidemiological and } \\
\text { statistical methods }\end{array}$ & & Primarily qualitative methods \\
\hline
\end{tabular}

Figure 1 First classification method.

reverse is seen to be equally true as our knowledge of the true meaning of a favourable environment continues to expand. This process of interpreting levels of living with states of health has, however, been mainly built up from observations upon the nature of 'static' relationships.

There is no question that, in studying a specific disease, the more searching test of the principles of social medicine is not the observance of a 'static' relationship but a dynamic one - the proof that health changes as social conditions change."

It is striking that those who developed social medicine in continental Europe do not appear to have had a major influence on these British views of social medicine. John Ryle did refer to Alfred Grotjahn and René Sand in his New York lecture ${ }^{10}$ but the British view of social medicine appears to have been formed primarily from British circumstances.

This then was the British vision of social medicine. What was the practice?

The practice of social medicine

Dorothy Porter has noted that the British Fournal of Social Medicine was dominated by epidemiological studies in its early years, and that interdisciplinary and sociological research was not well represented. ${ }^{2}$ This observation has now been explored by analysing the 77 papers which appeared during the five year period from 1947 to 1951 . Unsurprisingly, many of the papers deal with population groups within the armed forces including two on sickness, stress, and fatigue among RAF pilots. There is a sprinkling of studies of other occupational categories; one considers the incidence of disease on whaling expeditions. And there are many papers concerned with infant and child-

Table 1 First classification of papers appearing in the British Journal of Social Medicine in the period 1947-51

\begin{tabular}{lc}
\hline Category & $\begin{array}{l}\text { Number } \\
\text { of papers }\end{array}$ \\
\hline 1 Clinical and laboratory work applied to individuals or small groups & 1 \\
2 Aetiology and treatment of the acute and chronic infectious diseases & 12 \\
3 Studies of the aetiology and treatment of the non-infectious diseases & 64 \\
using primarily epidemiological and statistical methods & 0 \\
$\begin{array}{l}\text { Studies of the aetiology and treatment of the non-infectious diseases } \\
\text { using primarily qualitative methods }\end{array}$ & \\
\hline
\end{tabular}

hood morbidity and mortality. The selection of papers in the box below gives a flavour of the range of material.

\section{Selection of papers from the British} Journal of Social Medicine, 1947-51

Epidemiology of infective hepatitis among Allied Troops in Italy. McKinley PL, Truelove SC (January 1947)

Variations in occupational mortality between and within the social classes. Sutherland I (April 1947)

A study of the incidence of disease in a whaling expedition to the Antarctic Pelagic whaling grounds 1946-47. Case RAM (January 1948)

Sickness and stress in operational flying. Reid DD (Oct 1948)

Mortality from rheumatic heart disease in children and young adults in England and Wales. Knowelden J (January 1949)

Milk-borne infections in Great Britain. Savage W (April 1949)

Spread of tuberculosis from house to house. Webb J, Stewart A. With a statistical appendix by Sutherland I (January 1951)

All the papers are now classified in order to analyse what kinds of studies took place. Two methods of classification have been used.

\section{FIRST CLASSIFICATION}

First a classification system is applied which is illustrated in figure 1. A division is initially made between clinical and laboratory work applied to individuals, and studies of populations. The latter could be considered a broad definition of social medicine, and this is separated into the aetiology and treatment of the infectious and non-infectious diseases. Ryle emphasised the importance of the study of the non-infectious diseases together with the study of health itself. These studies can use either quantitative or qualitative methods, and this is the basis of the final division. The results of the first classification are shown in table 1. All but one consider the health of populations, and therefore can be included in the broadest definition of social medicine. Twelve are concerned with infectious diseases, and 64 with non-infectious diseases. (A small number of papers dealt with both infectious and noninfectious diseases and these have been included in the non-infectious category.)

A large majority of these papers therefore are within Ryle's definition of social medicine as being centrally concerned with population studies of the non-infectious diseases. However all of these studies use quantitative techniques. None use qualitative methods.

George Rosen, ${ }^{1}$ observed in 1947 ,

"It still remains to be seen to what extent the British workers will actually utilise sociological concepts and methods for the exploration of specific problems; and whether they will endeavour to see how the available knowledge of the social sciences can be put to use to improve health. For the present 
Table 2 Second classification of papers appearing in the British Journal of Social Medicine in the period 1947-51

\begin{tabular}{ll}
\hline Category & $\begin{array}{l}\text { Number } \\
\text { of papers }\end{array}$ \\
\hline 1 Studies of the social aetiology or treatment of ill health & 26 \\
2 Other work & 51 \\
\hline
\end{tabular}

it is significant, however, that in 1945 the Institute of Social Medicine at Oxford had a medical social worker on its staff, but no social scientist (sociologist, anthropologist or economist)."

Sociological techniques include both qualitative and quantitative methods, but the absence of qualitative methods indicates that the optimistic picture of research innovation painted by some of the pioneers in the mid 1940 s did not initially become a reality.

\section{SECOND CLASSIFICATION}

The second method of classification divides the papers between those concerned with the social causes or social treatment of disease and all others. Included in the social category are papers about social factors (including occupational) or social contributions which can not be reduced simply to the biological. The result of this simple division is shown in table 2 . The results are striking as only one third of the papers can be considered as dealing directly with social medicine, and are disappointing in light of the ambitions for the subject.

\section{Why did the term social medicine fall from favour?}

In the early 1950 s a series of conferences on social medicine sponsored by the Nuffield Foundation took place, at which the deans of many of the British faculties of medicine and medical schools met with others directly and indirectly involved in the teaching of social medicine. Here it was recognised ${ }^{13}$ that,

“. . . the existence has been established of a sphere of medicine which is not to be exhaustively described in terms of any of the hitherto recognised fields, and its generally accepted name is social medicine ...."

The future tasks for social medicine were seen to include the investigation of the aetiology of new epidemics; dealing with demographic changes which had happened and were expected, and contributing to the establishment of new types of health centres. At these conferences it was universally recognised, however, that for such purposes the subject was still in its infancy.

In the event, however, the label "Social Medicine" gradually became less commonly used through the remainder of the 1950 s and the 1960s. This was reflected in the change in title of this journal in 1953 to the British fournal of Preventive and Social Medicine. Why was this flourish of activity so short lived? In part this could be seen to reflect the death or change in interest of some of the leading protagonists. John Ryle died in 1950 and in the same year Richard Titmuss took the chair of social administration at the London School of Eco- nomics, which led to a change in his interests. The output of the Medical Research Council Social Medicine Research Unit changed from reports describing the social origins of disease to reports of potential mechanisms, such as how behaviours contributed to the apparently rising epidemic of coronary heart disease, ${ }^{14}$ the potential contribution of genetics to the aetiology of hypertension, ${ }^{15}$ and the contribution of water hardness to cardiovascular disease risk. ${ }^{16}$

Thomas McKeown's work turned increasingly to historical demography, which, while contributing greatly to the demonstration of the essentially social nature of mortality risk, did not have any obvious direct implications for the current practice of medicine or the organisation of health services. ${ }^{17}$

The achievements of the much-heralded Institute of Social Medicine at Oxford were considered to be disappointing by several observers. ${ }^{13}$ In 1951 the $B M \mathcal{F}$ editorialised ${ }^{18}$ that,

"It is too early to attempt an objective assessment of what has been achieved, and the thoughtful observer may still be in two minds about whether discussion of recent advances in social medicine is to be regarded as encouraging evidence of progress or as an example of whistling to keep up one's spirits".

Writing in the same year Iago Galdston ${ }^{19}$ summarised the opinions of some commentators on social medicine as

". . . 'much ado about little' - and the sport of those who love to pour old wine into new bottles."

The authoritative voice of Lord Horder expressed the conviction that the notion which underlay this new branch of medicine had not justified itself. Horder ${ }^{20}$ considered that the Oxford Institute had not survived the pressure of the financial stringency of the early 1950 s because others besides him did not regard,

“. . . the segregation of 'social, genetic and environmental factors in the incidence of human disease and disability' - to quote its governing phrase - as helpful in the general advance of medicine".

More fundamentally, the broader environment in which social medicine was reborn had changed. As the Second World War progressed great hopes for the future developed. In his Harveian oration to the Royal College of Physicians of London in 1942, William Wilson Jameson ${ }^{21}$ observed,

"Most of us who served in the period 1914-18 can recall how we looked forward to the time when we should return to the kind of life we had been leading before enlistment, to the practices or the appointments we had left, eager to get back to things as we knew them before the war clouds burst. Not so in this war. There is everywhere a conviction that great changes lie ahead of us and a desire so to plan the measures designed to meet the national emergency that some permanent good may be derived from them when the world is once again at peace."

This hope for better and fairer times, reflected in Labour's landslide victory in the 1945 general election and the establishment in 1948 of the National Health Service, was short lived. 
Table 3 First classification of papers appearing in the Journal of Epidemiology and Community Health in 1995

\begin{tabular}{ll}
\hline Category & $\begin{array}{l}\text { Number } \\
\text { of papers }\end{array}$ \\
\hline 1 Clinical and laboratory work applied to individuals or small groups & 0 \\
2 Aetiology and treatment of the acute and chronic infectious diseases & 5 \\
3 Studies of the aetiology and treatment of the non-infectious diseases & 66 \\
using primarily epidemiological and statistical methods & 0 \\
$4 \begin{array}{l}\text { Studies of the aetiology and treatment of the non-infectious diseases } \\
\text { using primarily qualitative methods }\end{array}$ & 23 \\
5 Health services research and method papers & 23 \\
\hline
\end{tabular}

By 1953 Lord Horder ${ }^{20}$ could hang his disapproval of social medicine on the fact that Ryle,

". . . got this thing mixed up with his political views, which were markedly socialistic".

The lack of concentration on the social causes and treatment of ill health, the focus on quantitative methods, and the difficulty of creating and maintaining balanced interdisciplinary teams, all made it easier for critics to say that social medicine was nothing new. An example of this is an editorial in the Medical Officer in $1948 .^{22}$ This supported the removal of responsibility for local authority hospitals from medical officers of health (MOsH). The view was expressed that this responsibility had taken up a considerable amount of the time of $\mathrm{MOsH}$ and that consequently they did not have enough time for preventive medicine. The editorial went on:

"That it did so, we suspect, else we should never have heard of the 'discovery' of social medicine which had been for a century the chief everyday work of the medical officer."

Indeed there was little support for social medicine from the MOsH. Jane Lewis's discussion of the alienation between the academics of social medicine and the practitioners of public health is illuminating. ${ }^{23}$. The MOsHs - represented through their society on the editorial board of the British Fournal of Social Medicine - retained a somewhat cynical view of their colleagues in social medicine, who were seen to be excessively academic and dogmatic. At times there was outright hostility. One example was the Medical Officer's caustic review of the report of the Oxford Institute of Social Medicine for the period $1943-50 .{ }^{24}$ The report had made some criticisms of the work of infant welfare centres, and the Medical Officer responded:

"Here the medical personnel concerned sincerely believe themselves to be doing 'social medicine' but apparently it is not so - they may see the mothers regularly, they may visit the homes, they may be entrusted with many intimate confidences bearing on the environmental conditions all of which affect their care of the infant and its development, but this is not enough because 'no note is made of the social class of babies! Too bad."

Finally social medicine had little impact on the medical schools. William Wilson Jameson led an attempt to reform medical education so that new doctors would be capable of practising social medicine. Firm proposals were made before the end of the Second World War but were not successfully implemented. ${ }^{25}$
From social medicine to community health: the Journal today

The practice of social medicine, as reflected in the pages of the early volumes of the Journal, could be said to fail to live up to the excited and expansionist rhetoric of its main proponents. In the succeeding half-century, medically qualified public health practitioners have traded under different names - "specialists in community medicine" from 1974 and now "consultants in public health medicine" - and the grand visions of pioneers such as Ryle, Hogben, and Crew seem almost quaint. Some appear to want to celebrate the desocialisation and parochialisation of public health brought about by its contraction into an advisory group for health service purchasers. ${ }^{26}$ The Journal has changed with the times, its name tailing the speciality of community medicine after its establishment by changing its name to the fournal of Epidemiology and Community Health. How, however, has the content of the Journal changed over this period?

The 1995 volume was examined and the 94 full articles classified in the same way as was done for the first five years of the British fournal of Social Medicine. The results are shown in tables 3 and 4 . Papers on health services research and methodology now appear (there was only one such paper in the first five years of the Journal) and as these do not easily fit into the classification schemes a separate category has been created for them. Again some feel for the types of studies is given by the selection of titles presented in the box below.

\section{Selection of papers from the Journal of Epidemiology and Community Health 1995}

Childhood socioeconomic status and risk of cardiovascular disease in middle aged US women: a prospective study. Gliksman MD, Kawachi I, Hunter D et al (February 1995) Mammography screening: an incremental cost effectiveness analysis of two view versus one view procedures in London. Bryan S, Brown J, Warren R (February 1995)

Prevalence of hepatitis B virus (HBV) infection in Singapore men with sexually transmitted diseases and HIV infection: role of sexual transmission in a city state with intermediate HBV endemicity. Heng BH, Goh $\mathrm{KT}$, Chan $\mathrm{R}$ et al (June 1995)

Alcohol consumption, diet, coronary risk factors, and prevalent coronary heart disease in men and women in the Scottish heart health study. Woodward M, Tunstall-Pedoe $\mathrm{H}$ (August 1995)

Venous ulcer healing: effect of socioeconomic factors in London. Franks J, Bosanquet $\mathrm{N}$, Connolly $\mathrm{M}$ et al (August 1995) Socioeconomic factors and mortality in urban settings: the case of Barcelona, Spain. Borrell C, Arias A (October 1995)

Sample sizes for studies using the short form 36 (SF-36). Julious SA, George S, Campbell MJ (December 1995) 
Table 4 Second classification of papers appearing in the Journal of Epidemiology and Community Health in 1995

\begin{tabular}{ll}
\hline Category & $\begin{array}{l}\text { Number of } \\
\text { papers }\end{array}$ \\
\hline 1 Studies of the social aetiology or treatment of ill health & 46 \\
2 Other work & 25 \\
3 Health services research and method papers & 23 \\
\hline
\end{tabular}

Table 5 Comparison of periods 1947-51 and 1995 using the second classification method

\begin{tabular}{lll}
\hline Category & $\begin{array}{l}\text { Period } \\
\text { 1947-51 }\end{array}$ & 1995 \\
\hline Studies of the social aetiology or treatment of ill health & 26 & 46 \\
All other work (including health services research and methodology) & 51 & 48 \\
\hline
\end{tabular}

If tables 1 and 3 are compared, apart from the presence now of papers on health services research and methodology, the distribution of papers between the categories is similar. In both periods the majority of papers are studies of the aetiology and treatment of the noninfectious diseases using primarily epidemiological and statistical methods. There are no papers mainly using qualitative methods.

However, comparison of tables 2 and 4 shows, perhaps surprisingly, that there is now a greater proportion of papers which report studies of the social aetiology or treatment of ill health. This comparison is summarised in table 5.

Despite the fall from favour of the term social medicine, the importance of the social environment continues to be recognised and this is reflected in current research. Thus the Department of Health's 1995 report on variations in health ${ }^{27}$ states,

"It is likely that cumulative differential exposure to health damaging or health promoting physical and social environments is the main explanation for observed variations in health and life expectancy, with health related social mobility, health damaging or health promoting behaviours, use of health services, and genetic or biological factors also contributing."

The report goes on to say,

"An important way of achieving the Health of the Nation targets is to improve the health of the least healthy groups closer to the levels attained by the most healthy groups."

"What is now needed is for the NHS at local level to undertake a more systematic identification of health variations and to design and implement measures to tackle them."

While signs of actual governmental action are limited, ${ }^{28}$ the official acknowledgement of social differentials in health is important after nearly two decades of obfuscation.

\section{Conclusions}

An analysis of the papers appearing in the British fournal of Social Medicine in its first five years suggests that the practice of social medicine failed to live up to the aspirations of its main proponents with respect to the scope, multidisciplinary nature and impact of the work.

Several contributors to the fall from favour of the term "social medicine" can be discerned: the optimistic mood in society in the immediate post-war period faded; some of the leading protagonists of social medicine died or changed the focus of their interests; social medicine was criticised as contributing little that was new or of importance; there was little support from the MOsH; and little impact was made on medical education, leading to few trained practitioners having a commitment to the vision of social medicine.

Over the years leading up to the Second World War, the MOsH increasingly moved into medical administration and the running of personal health services. This detachment from traditional public health concerns meant they had little overall impact in this regard. The mid-century growth of interest in social medicine may have partly reflected the fact that the "official" public health functionaries were so detached from the real public health function. A similar story is unfolding today ${ }^{29}{ }^{30}$ with Public Health Medicine being mainly interested in purchasing of health services, medical administration and medical audit. Some have called for a "New Public Health" movement, ${ }^{31}$ with an explicitly broader basis. This, together with the grudging governmental acknowledgement of health variations, could create a space within which the mid-century broader vision of social medicine could reappear. The content of this Journal reflects the fact that interest has not dissipated. Continuing to concentrate on the key concerns of social medicine could guarantee another half-century of relevance.

1 Rosen G. What is social medicine? A genetic analysis of the concept. Bulletin of the History of Medicine 1947;21: 674-733.

2 Porter D. Changing disciplines: John Ryle and the making of social medicine in Britain in the 1940s. History of Science 1992;30:137-64

3 Mielck A. "Soziale Medizin": Die Diskussion zu Beginn des 20. Jahrhunderts. In: Mielck A, ed. Krankheit und soziale Ungleicheit: Sozialepidemiologische Forschungen in Deutschland. Opladen: Leske \& Budrich, 1994:35-52.

4 Proctor RN. Racial hygiene. Medicine under the Nazis. Cambridge, Massachusetts: Harvard University Press, 1988.

5 Porter D. Introduction. In: Changing disciplines: lectures on the history, method, and motives of social pathology. New Brunswick and London: Transaction Publishers, 1994: xi-xxix.

6 Oakley A. Eugenics, social medicine and the career of Richard Titmuss in Britain 1935-50. British fournal of Sociology 1991;42:165-94.

7 Vernon HM. Health in relation to occupation. London: Oxford University Press, 1939.

8 Buzzard F. The place of social medicine in the reorganisation of health services. BMf 1942;I:703-4.

9 Ryle JA. Social medicine: its meaning and scope. BMF 1943; ii:633-6.

10 Ryle JA. Social pathology. In: Iago Galdston, ed. Social medicine its derivations and objectives. New York: The Commonwealth Fund, 1947:55-124.

11 Crew FAE. Social medicine: an academic discipline and an instrument of social policy. Lancet 1944;ii:617-9.

12 Morris JN, Titmuss RM. Health and social change: 1 The recent history of rheumatic heart disease. The Medical

13 Galdston I. The meaning of social medicine. Cambridge, Massachusetts: Havard University Press, 1954

14 Morris JN, Heady JA, Raffle PAB. Physique of London busmen: epidemiology of uniforms. Lancet 1956;ii:56970

15 Morrison SL, Morris JN. Epidemiological observations on high blood-pressure without evident cause. Lancet 1959; ii:864-70.

16 Morris JN, Crawford MD, Heady JA. Hardness of local water supplies and mortality from cardiovascular disease. Lancet 1961;i:860-2.

17 McKeown T, Brown RG. Medical evidence related to English population changes in the eighteenth century. Population Studies 1955;9:119-41.

18 Anonymous. Social medicine. Editorial. BMF 1951;I:1197.

19 Galdston I. Social medicine and the epidemic constitution. Bulletin of the History of Medicine $1951 ; \mathbf{X X V}: 8-21$. 
20 Lord Horder. Fifty years of medicine. London: Gerald Duckworth \& $\mathrm{Co}, 1953$.

21 Jameson W. War and the advancement of social medicine. Lancet 1942;ii:475-80.

22 Anonymous. The MOH and the hospital boards. Editorial. The Medical Officer 1948;79:258-9.

23 Lewis J. The medical journals and the politics of public health 1918-90. In: Bynum WF, Lock S, Porter R, eds. Medical journals and medical knowledge: historical essays. London and New York: Routledge, 1991:207-27.

24 Anonymous. The Oxford Institute of Social Medicine. Editorial. The Medical Officer 1951;85:12.

25 Oswald NTA. A social health service without social doctors. Social History of Medicine 1991;2:295-315.
26 Eskin F. Sex, violence and PHPs. The Public Health Physician 1992;3(3):1-2.

27 Variations Sub-Group of the Chief Medical Officer's Health of the Nation Working Group. Variations in health: what can the Department of Health and the NHS Do? London: Department of Health, 1995.

28 Davey Smith G, Morris J. Increasing inequalities in the health of the nation. $B M F$ 1994;309:1453-4

29 Whitty P, Jones I. Public health heresy: a challenge to the purchasing orthodoxy. $B M \mathcal{F}$ 1992;304:1039-41.

30 Davey Smith G. "The Health of the Nation" and The PHP. The Public Health Physician 1993;4(1):4-5. 31 Ashton J, Seymour H. The new public health: the Liverpool
experience. Milton Keynes: Open University Press, 1988. 